\title{
ACESSIBILIDADE E ENTORNO COMO DIRETRIZES DE ESPAÇOS LIVRES PÚBLICOS
}

\author{
ACCESSIBILITY AND SURROUNDING AS GUIDELINES OF PUBLIC OPEN SPACES
}

José Roberto Merlin*

Flávia Aceituno Carneiro**

\begin{abstract}
RESUMO
A pesquisa objetiva compreender e explorar ideias vinculadas ao "potencial educador dos espaços públicos" com ênfase na acessibilidade e nas relações com o entorno, estudando um espaço na cidade de Sorocaba (SP), membro da Associação Internacional das Cidades Educadoras - AICE, hoje coordenadora dessa Associação no Brasil. Foram percorridos seus espaços públicos através do programa "Roteiro Educador", que subdividiu a cidade em cenários que enfatizam quatro temas: cultural, histórico, social e ecológico. Neste processo foi recortado - Parque das Águas, pertencente ao Roteiro Educador Ecológico, buscando compreender suas potenciais qualidades educadoras vinculadas às características espaciais. Balizados por estes parâmetros, buscou-se enfatizar elementos compositivos do espaço público como ferramentas analíticas para investigar eventuais interferências do projeto em padrões do tecido urbano como totalidade, tentando desvelar qualidades educadoras inerentes ao espaço. Entende-se que as proposições de desenho urbano em áreas livres podem interferir como agentes educadores estruturadores da qualidade dos espaços públicos como um todo, aprimorando a esfera de vida pública.
\end{abstract}

Palavras-chave: Espaços livres públicos. Potencialidades educadoras. Cidades educadoras. Acessibilidade. Requalificação urbana.

\begin{abstract}
The research aims to understand and explore ideas linked to "potential educator of public spaces" with an emphasis on accessibility and relationships with the environment, studying an area in the city of SorocabaSP, AlCE-member International Association of Educating Cities, now coordinator of this Association in Brazil. Were surveyed its public spaces through the "Roadmap Educator" which subdivided the city into
\end{abstract}

* $\quad$ Arquiteto, mestre e doutor pela Faculdade de Arquitetura e Urbanismo da Universidade de São Paulo (FAUUSP). Professor pesquisador do Grupo de Pesquisa Requalificação Urbana do Centro de Ciências Exatas, Ambientais e de Tecnologia da Pontifícia Universidade Católica de Campinas (CEATEC PUC/Campinas). Centro de Ciências Exatas, Ambientais e de Tecnologia. Campus I, Rodovia D. Pedro I, km 136, Parque das Universidades, 13086-900, São Paulo, SP, Brasil.

jrmerlin@puc-campinas.edu.br

** Graduando em Arquitetura e Urbanismo da Faculdade de Arquitetura e Urbanismo da Pontifícia Universidade Católica de Campinas. Bolsista de Iniciação Científica (FAUPUC-Campinas).

Rua Pedro José Ribeiro, 35, Vila Carvalho, 18060-210, Campinas, SP, Brasil.

flavia.ac@puccampinas.edu.br 
scenarios that emphasize four themes: cultural, historical, social and ecological. This process was cut the "Water Park", belonging to the Ecological Roadmap Educator, trying to understand its potential qualities educators linked to spatial features. Marked by these parameters was sought to emphasize compositional elements of public space as analytical tools to investigate possible interference urban design standards of the urban fabric as a whole, trying to unveil educators qualities inherent to space, understanding that the propositions of urban design in free areas may interfere as structuring agents of quality in public areas as a whole, improving the public sphere of life.

Keywords: Public open spaces. Potential educators. Educating cities. Acessibility. Urban requalification.

\section{INTRODUÇÃO: SOBRE SOROCABA}

A região do rio Sorocaba foi habitada pelos tupiniquins, tendo sido ponto de passagem do caminho conhecido como "Peabiru", utilizado por silvícolas de toda a América Latina e que, mais tarde, foi utilizado pelos bandeirantes e pelos missionários. Adentrando pelos sertões, ambos promoveram a expansão do território brasileiro.

Em 21 de abril de 1660, Baltazar Fernandes, possuidor das terras em sesmarias, doou aos monges de São Bento a capela Nossa Senhora da Ponte (atual Igreja Sant'Ana), fundando Sorocaba. Posteriormente, doou significativa gleba de terras aos monges beneditinos, sob a condição de construírem convento e escola para atrair moradores da região, iniciando o processo de urbanização.

Cronologicamente, os ciclos de Sorocaba começam no bandeirismo, passando pelo tropeirismo - com sua famosa Feira de Muares, que ganhou âmbito nacional-, pela industrialização inicial no ramo têxtil, pela diversificação industrial recente, que ganha fôlego a partir da construção da rodovia Castelo Branco no início da década de 1970. A cidade consolida seu desenvolvimento no século XXI como polo de atração de inúmeras indústrias de média e alta tecnologia e, hoje, festeja aumentos significativos de arrecadação - fruto da diversidade e da capacidade de seu parque industrial, com indústrias de alta tecnologia, e por conseguir investimentos públicos e privados na inauguração de diversas universidades.

A cidade associou-se à Associação Internacional de Cidades Educadoras (AICE), criada no ano de 1990, em Barcelona, e que hoje congrega mais de 400 cidades em 35 países. A entidade procura agregar cidades do mundo todo, objetivando trocar experiências em todos os setores e atividades da gestão urbana, especialmente enfatizando questóes educadoras para responder aos ditames da chamada "sociedade do conhecimento", trazida pela globalização. Também procura defender os valores locais, aumentar a participação do cidadão na gestão pública, incrementar processos de ações coletivas, dilatar o sentimento de pertencimento e cidadania, fomentando processos proativos e democráticos nas ações e transformações urbanísticas. (AICE, 1990).

Adotada a política para transformar-se em cidade educadora, Sorocaba inventariou seus bens, valores e patrimônios criando "quatro roteiros" a serem percorridos de forma organizada e didática, nos quais se percebem propostas que enfatizam determinado tema, criando cenários que ilustram questões culturais, históricas, sociais e ecológicas. 


\section{SISTEMAS DE ESPAÇOS LIVRES PÚBLICOS DE SOROCABA}

Cidade Educadora desde 2006, Sorocaba implantou o "Roteiro Educador", onde se encontram edifícios históricos, parques e praças que revelam a história da cidade e oferecem cenários que, potencialmente, educam os usuários, como a igreja Sant'Ana, o Mosteiro São Bento, o Palácio Scarpa, o Casarão Brigadeiro Tobias, o Chalé Francês, a Estação Ferroviária. $\bigcirc$ mesmo ocorreu com os roteiros ecológicos, sociais e culturais, permitindo percursos que pretendem educar a população de todas as faixas etárias.

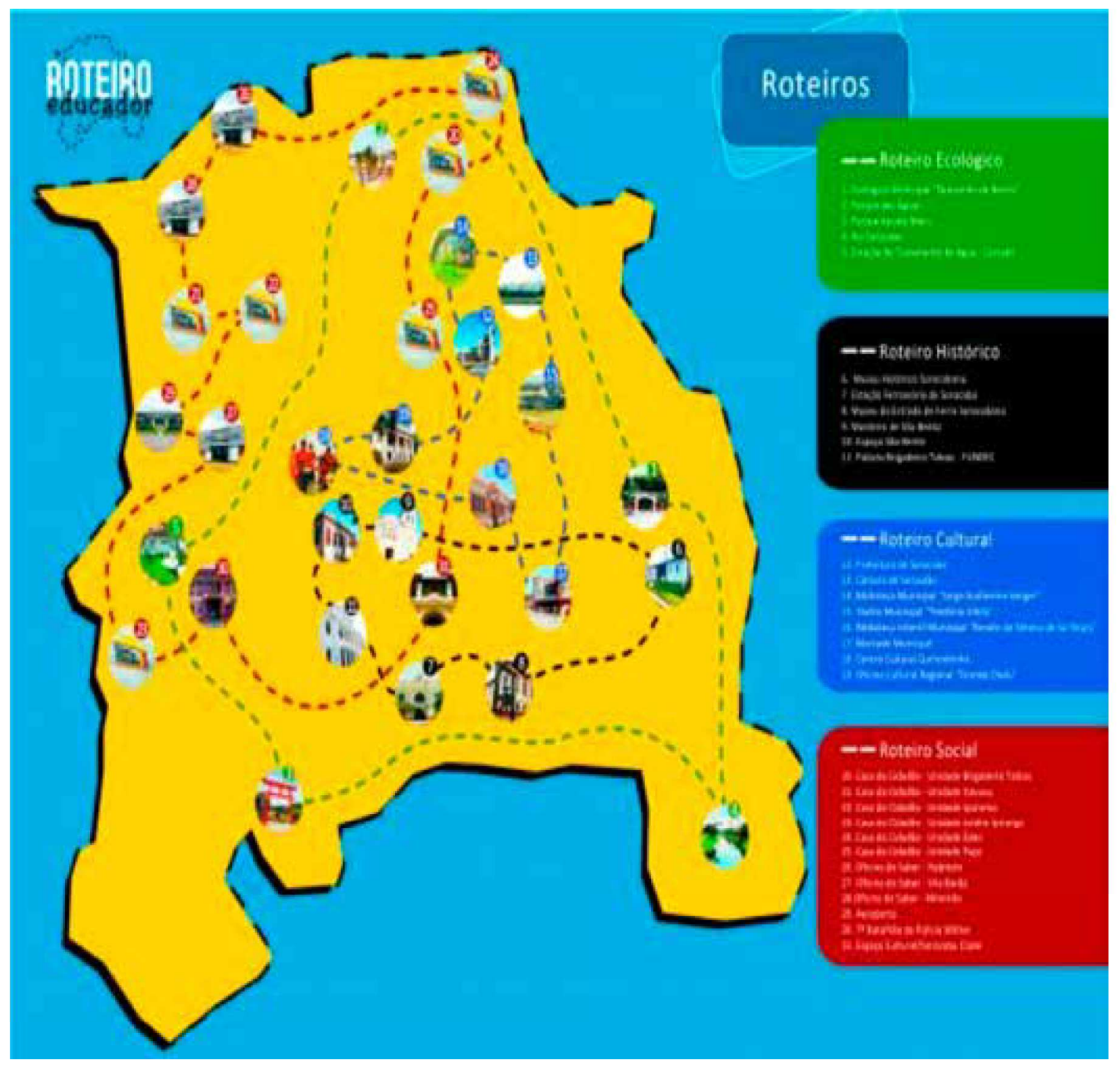

Figura 1 llustração dos quatro roteiros educadores.

Fonte: Prefeitura de Sorocaba. Disponível em: <http://www.sorocaba.sp.gov.br/portal/>. Acesso em: 2 jul. 2013.

Em 2008, foi assinado o Acordo de Cooperação Interinstitucional Cultural e Científica entre a Fundação para a Pesquisa em Arquitetura e Ambiente (FUPAM), o Laboratório de Paisagem da Faculdade de Arquitetura e Urbanismo da Universidade de São Paulo (FAUUSP), a Faculdade de Arquitetura e Urbanismo da Universidade Paulista de Sorocaba (FAU-UNIP) e a prefeitura de Sorocaba, configurando relações entre estas instituições com o objetivo de trocar informações e desenvolver programas 
de interesse comum, cujo principal produto foi uma densa proposição de diretrizes em relação ao sistema de espaços livres públicos da cidade de Sorocaba. $O$ cuidado deste acordo com a qualidade de vida vinculada às concepções espaciais fica nítido no trecho a seguir:

Atualmente, o município tem se dedicado à criação de um sistema de parques urbanos, eventualmente ligados à rede hídrica local, no sentido de recuperar as bacias urbanizadas e promover melhorias ambientais e estéticas no sistema de drenagem municipal. Exemplo desse processo são os parques: Vitória Régia, em uma área protegida junto às várzeas do rio Sorocaba; o parque Campolim, uma lagoa de controle de enchentes que se tornou o parque mais visitado da cidade; a ciclovia e o tratamento paisagístico da via marginal junto ao rio Sorocaba, que the atribui características de um parque linear. (GALENDER et al., 2012, p. 322).

Estes parques e outros espaços públicos conformaram uma estrutura de espaços públicos e caminhos que foram trabalhados e pensados junto com um sistema de transporte alternativo, valorizando outras possibilidades de locomoção, como as ciclovias. Para incrementar a utilização destas, a municipalidade montou um sistema de aluguel de bicicletas localizado em diferentes pontos da malha urbana, mas priorizando parques e praças.

Com a implantação dos parques e das áreas de uso coletivo ocorreram melhorias efetivas na qualidade da água e no sistema de drenagem urbano. Vazios urbanos foram se transformando em áreas públicas e privadas, que, agregadas, começam a desenhar um grande parque linear estruturado pelo rio Sorocaba e seus afluentes, articulado com as ciclovias sombreadas pela vegetação colocada nos parques. Definindo uma centralidade complementar e oposta aos espaços do centro histórico mais frequentados nos dias úteis - em consequência da maior disponibilidade de comércio e serviços-, o sistema de parques tem aumento constante de novos usuários, especialmente nos fins de semana.

\subsection{SOBRE O PARQUE DAS ÁGUAS "MARIA BARBOSA DA SILVA"}

De acordo com técnicos da prefeitura, foi criado o "Plano Cicloviário", com cerca de 100 quilômetros de ciclovias, conjuminado com a implantação de mais de vinte parques públicos, como o Parque das Águas, Ipiranga, Campolim, Formosa, Kasato Maru, Espanhóis, Ipês.

O Parque das Águas, objeto de estudo desta pesquisa, faz parte do roteiro ecológico, permanecendo aberto 24 horas por abrigar a sede da Guarda Municipal. Sua área é de $162.000 \mathrm{~m}^{2}$ e localiza-se entre os bairros Jardim Abaeté e Jardim Maria do Carmo, antiga área de inundação onde a taboa predominava como vegetação dominante. Envolvido por uma curva desenhada pelo leito do rio Sorocaba, o parque foi implantado, delimitado pelas águas do rio, e seu projeto sinuoso parece ter sido inspirado nas curvas do caminhar das águas definido pela natureza. 


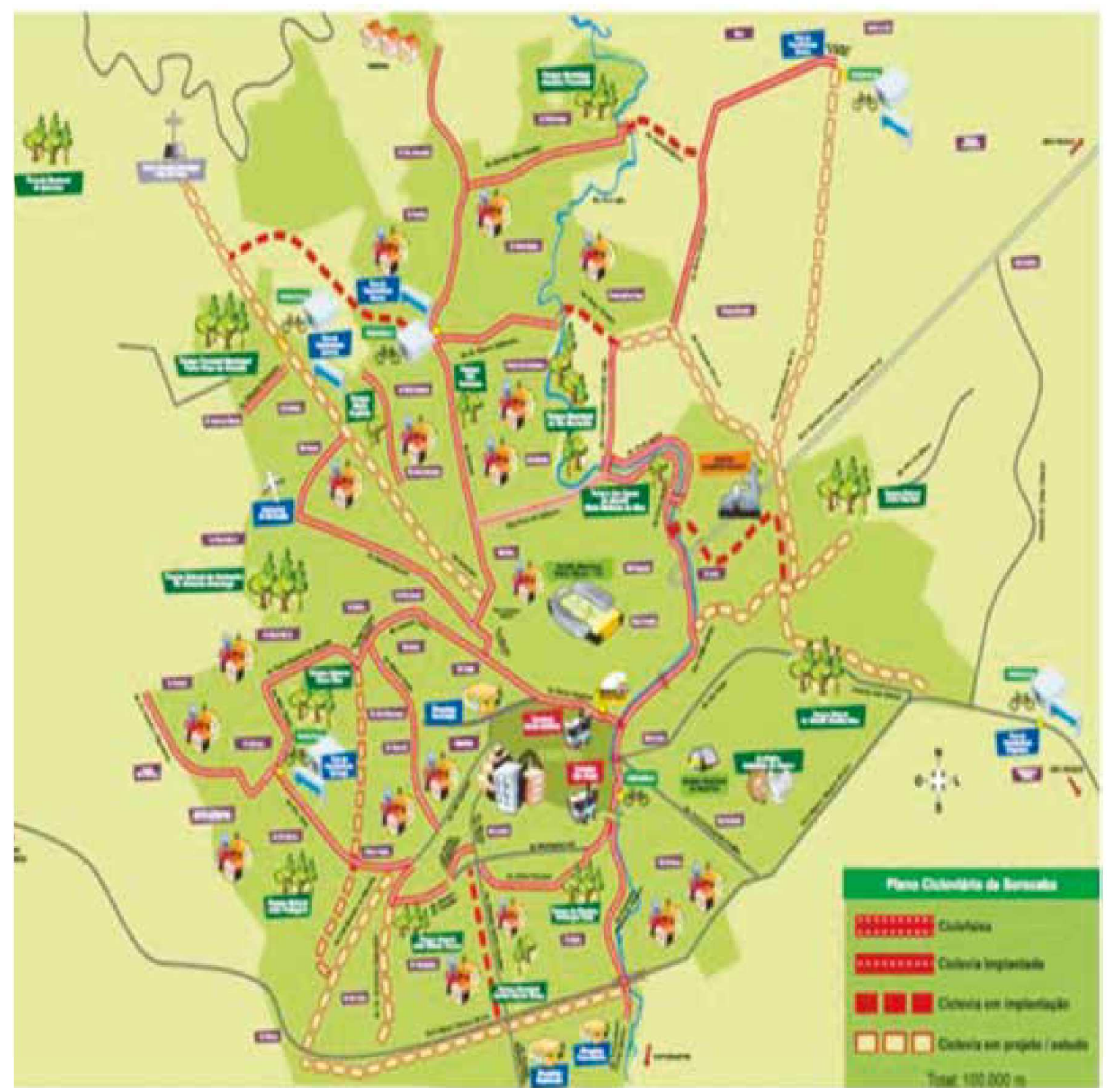

Figura 2 Mapa do sistema de ciclovias.

Fonte: Prefeitura de Sorocaba. Disponível em: <http://www.sorocaba.sp.gov.br/portal/>. Acesso em: 2 jul. 2013.

Nos bairros do entorno do Parque das Águas, as enchentes e alagamentos eram frequentes e os moradores eram forçados a abandonar suas casas. Para resolver a questão, o Serviço Autônomo de Água e Esgoto (SAAE) teve por prerrogativa construir barragens e "piscinões" que seriam tangenciados por outros equipamentos de uso coletivo, o que resultou na inauguração do Parque das Águas em 2008. Junto ao lago central criaram-se áreas de lazer com características específicas, como ponto de encontro, local para shows, academia ao ar livre, parque infantil e praças esportivas. Cumpriram-se dois objetivos: a regulagem da vazão das águas pluviais e a criação de uma grande área de lazer para a comunidade.

O parque, como acontece em todas as cidades, acabou valorizando todo o seu entorno, rodeado por residências de classe média baixa, uma vez que o local foi dotado de infraestrutura qualificada, ausente na maioria dos parques da cidade, ao agregar espaços e equipamentos que propiciam encontros vinculados ao lazer, ao esporte è̀ cultura, além de prover a segurança da região por conter a sede da Guarda Municipal. 


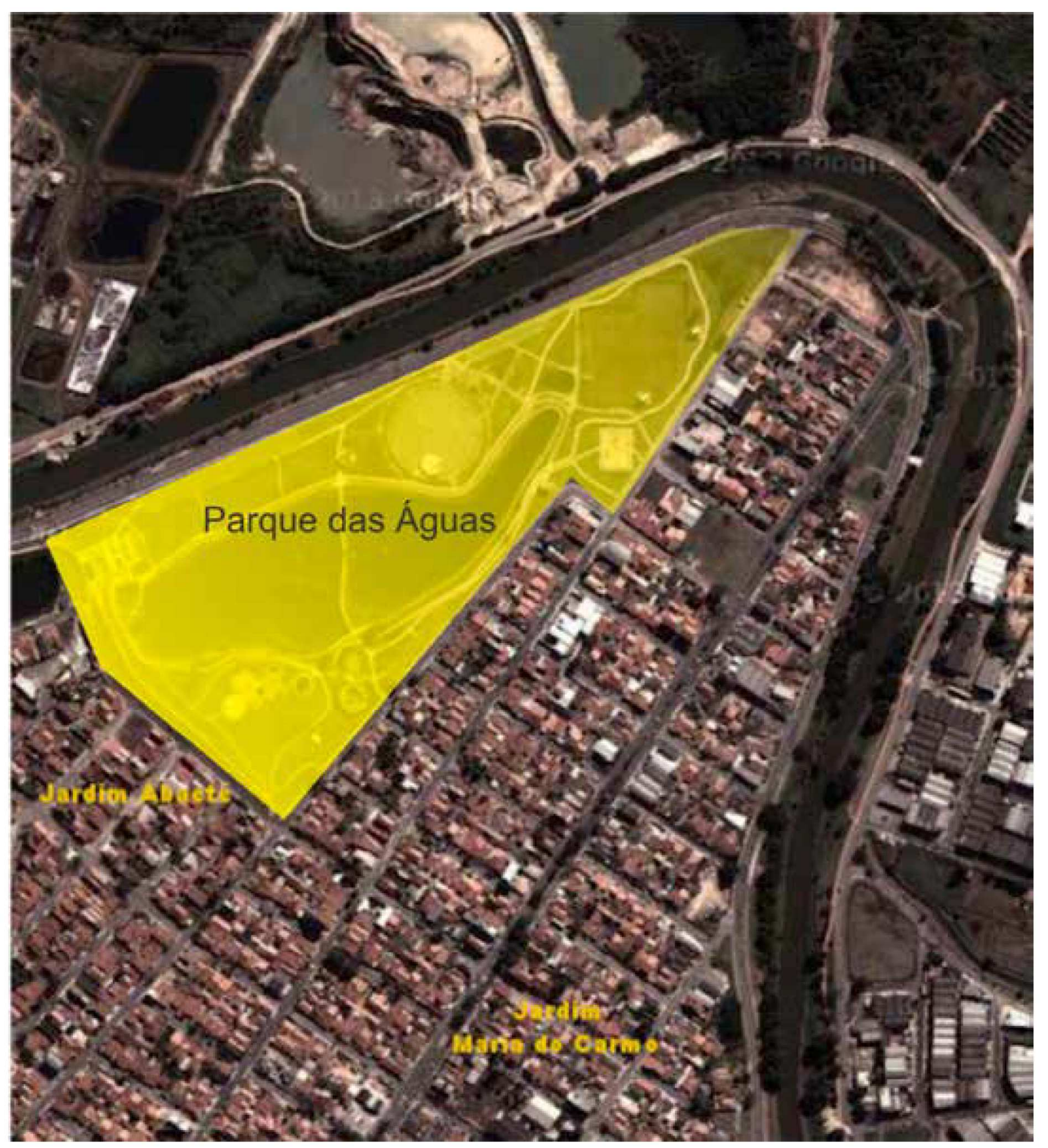

Figura 3 Parque das Águas e entorno.

Edição: José Roberto Merlin e Flávia Aceituno Carneiro.

Fonte: Google Earth. Disponível em: <https://www.google.com.br/maps/place/Parque+das+\%C3\%81guas/@23.4701 255,-47.4461316,17z/data $=$ !3m 1!4b1!4m2!3m1!1s0x94cf5ff787200fb 1:0x2ceac4fc5ecb87d6>. Acesso em: 4 mai. 2013.

O Parque das Águas conta com anfiteatro, praça de eventos, pista de skate, pista de caminhada, ciclovias, placas informativas sobre a fauna e flora ali existentes, parque infantil, academia ao ar livre, sistema de iluminação e quadra de areia, além de sediar o Integra Bike Sorocaba, onde as pessoas podem alugar bicicletas e deambular pela cidade. 


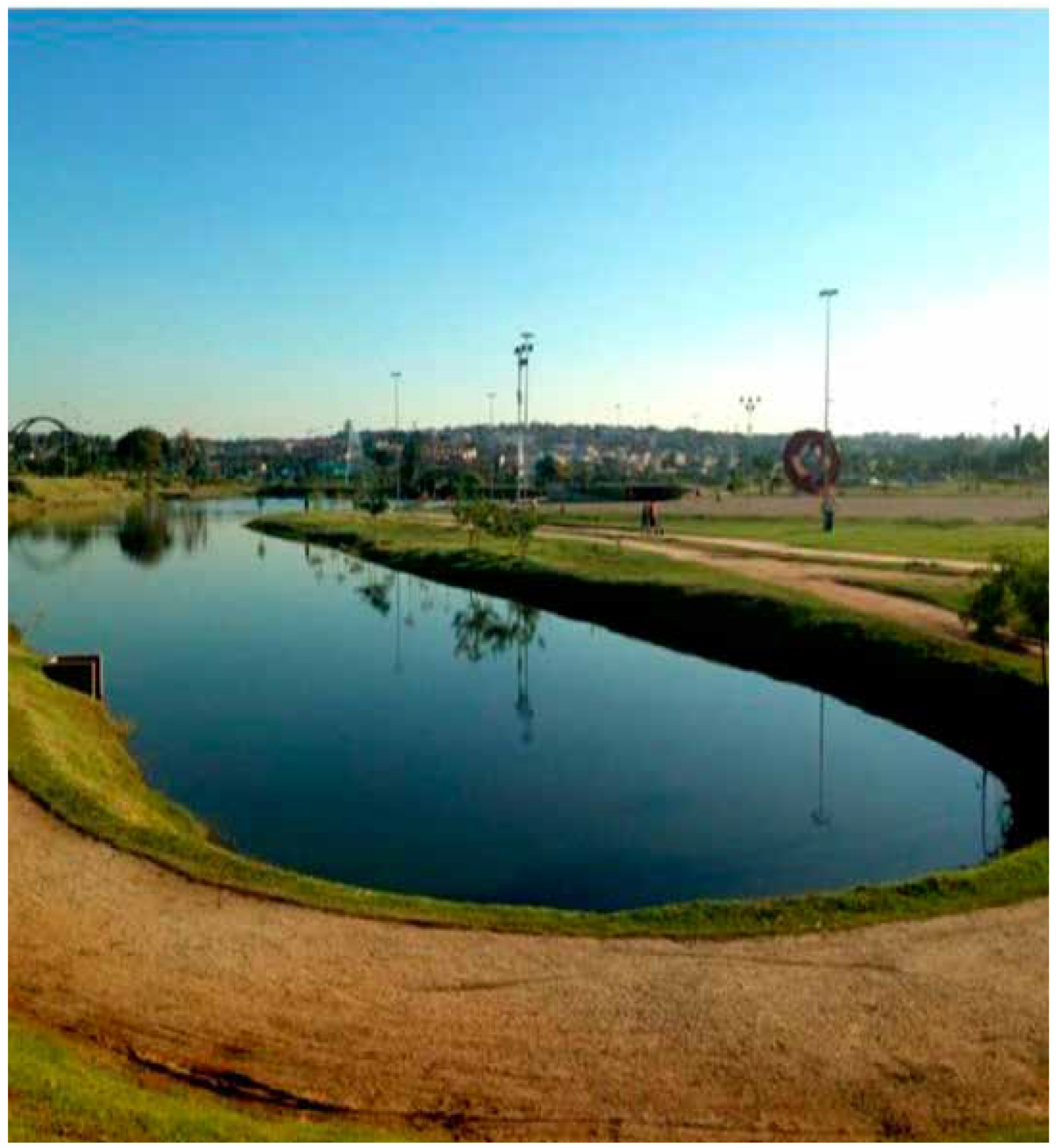

Figura 4 Lago estruturador do Parque das Águas. Foto: Flávia Aceituno Carneiro - 2013.

Além disto, o local tornou-se referência para maratonas de fins de semana, que atraem pessoas de toda a Sorocaba e de cidades próximas. $\bigcirc$ evento Pedala Sorocaba tem no parque seu ponto de apoio, assim como acontece com eventos sociais e culturais que exigem um espaço maior, como a Virada Cultural, da qual participaram cerca de 10 mil pessoas. 


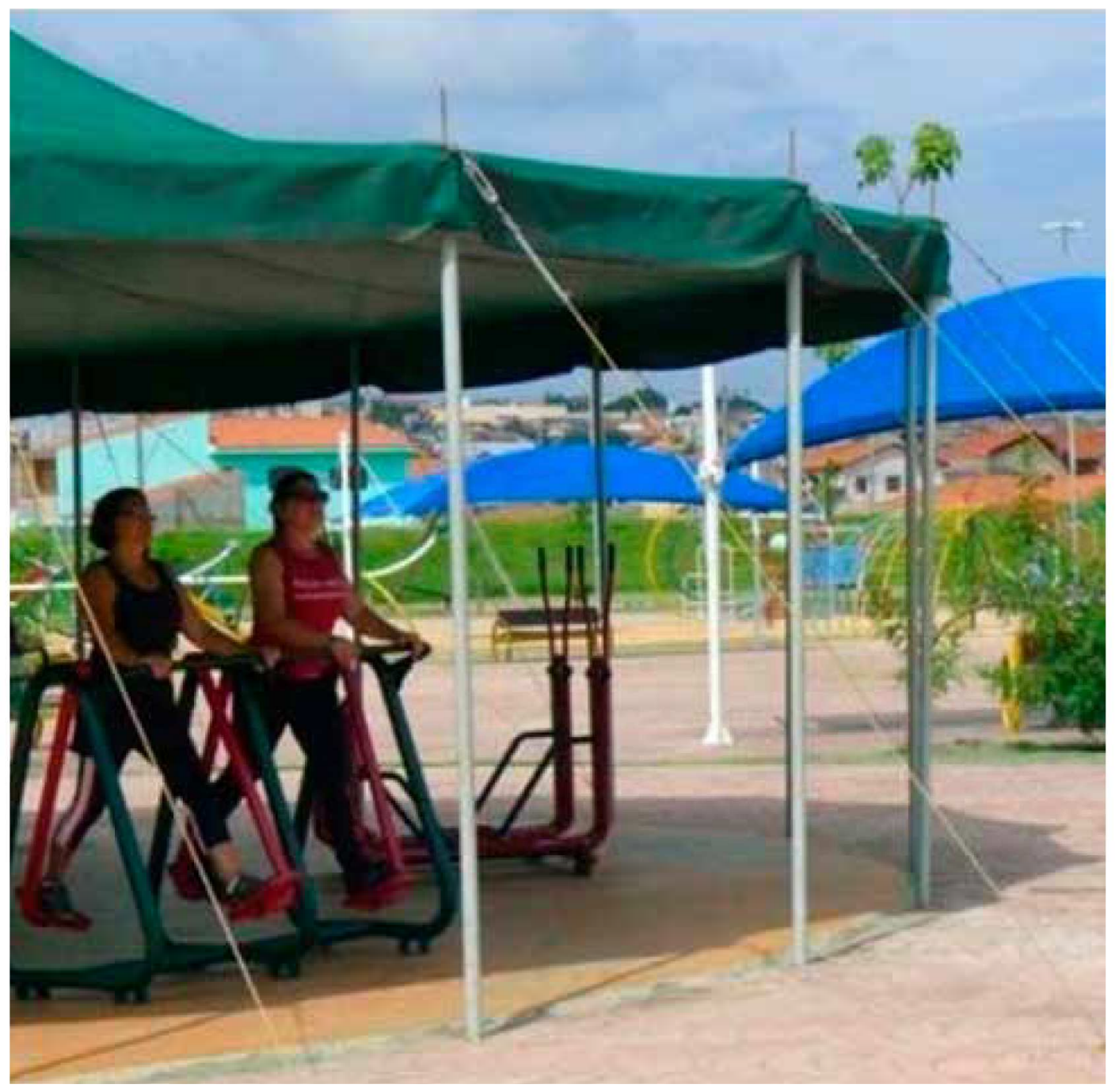

Figura 5 Academia ao ar livre e parque infantil no Parque das Águas. Foto: José Roberto Merlin - 2013.

A avenida Marginal Dom Aguirre é a principal via de acesso que liga o parque ao centro de Sorocaba e a outros bairros, sendo as demais ruas de tráfego local. Há fácil mobilidade para pedestres e ciclistas, cumprindo os quesitos básicos de acessibilidade universal- o que é facilitado pela topografia pouco acidentada.

\subsection{PROJETOS URBANÍSTICOS FUTUROS RELACIONADOS AO PARQUE DAS ÁGUAS}

Jardim Botânico de Sorocaba, inaugurado em 3/4/2014, localiza-se na margem oposta (direita) do rio Sorocaba, na mesma direção do Parque das Águas.

Duas áreas na margem direita do rio, uma onde se encontra um porto de areia particular e outra num antigo aterro sanitário, estão em processo de desapropriação e futuramente deverão integrar-se aos parques já existentes, formando um único conjunto com $700.000 \mathrm{~m}^{2}$.

É intenção da municipalidade que todos os parques da cidade se interliguem através das ciclovias, fazendo do rio Sorocaba o organizador de um parque linear 
em praticamente toda sua extensão, prevendo também o uso das áreas banhadas por seus afluentes. A prefeitura busca resolver os problemas de proteção e conservação das Áreas de Preservação Permanente (APP), oferecendo possibilidades de usos compatíveis - especialmente nas áreas limites, que tangenciam as áreas de uso mais restrito.

\section{ANÁLISE ESPACIAL DO PROJETO}

Fez-se a análise da obra levando em conta as peculiaridades formais e espaciais próprias das áreas abertas e baseadas em critérios analíticos da arquitetura enquanto campo disciplinar. Os principais parâmetros escolhidos como passíveis de compor a análise foram: estrutura; iluminação natural; volume e massa; circulação e uso do espaço; unidade e conjunto; repetitivo e singular; simetria e equilíbrio; geometria; adição e subtração; hierarquia. (CLARK; PAUSE, 1987).

Tais características são vetores inerentes à qualidade do espaço urbano e arquitetônico, normalmente conhecidos como "elementos permanentes da arquitetura", e estão estritamente ligados às práticas profissionais do arquiteto urbanista, por estabelecerem critérios de qualidade do espaço. Esta inerência faz com que as características arroladas, quando se considera a arquitetura urbana como produto cultural, sejam educadoras.

Sendo assim, é importante dilatar o entendimento do conceito de espaço, de forma que ultrapasse os limites da geometria, superando o objeto abjeto, usualmente denominado "espaço físico", metáfora de algo desarticulado, sem vida, sem marcas da história, da tecnologia, da organização social e de processos representativos simbólicos ligados à linguagem dos objetos. Algo que representa mera concreção pragmática, sem história, subvertendo a função de revelar fatos pregressos vinculados à construção da civilização, sendo, portanto, objetos informativos e formativos extrapolando o âmbito de mero objeto e contendo na sua subjacência as evidências das ações que os erigiram na multiplicidade de conexões.

Destarte, foram eleitos alguns critérios próprios e específicos para a análise crítica do Parque das Águas. Seu desenho mostra uma estrutura fortemente definida pelo lago central - "piscinão" de forma ameboide, com dimensões, nos dois eixos principais, próximas de 140 metros e 850 metros - que sintetiza a função mais precípua do projeto: fundamentalmente, evitar enchentes. Por seu tamanho, acabou ordenando as outras atividades do programa funcional, definindo a composição urbanística geral e articulando as unidades individualizadas, (polifunções) compondo um conjunto que define o parque.

Este processo gerou fluxos de circulação que contornam o lago e apenas uma vez o divide com uma passarela que permite atravessá-lo num percurso disposto perpendicularmente ao eixo maior. Os caminhos sinuosos interligam as áreas com funções bem definidas, criando um desenho que deu um tom sinuoso, tentacular e orgânico ao conjunto. 


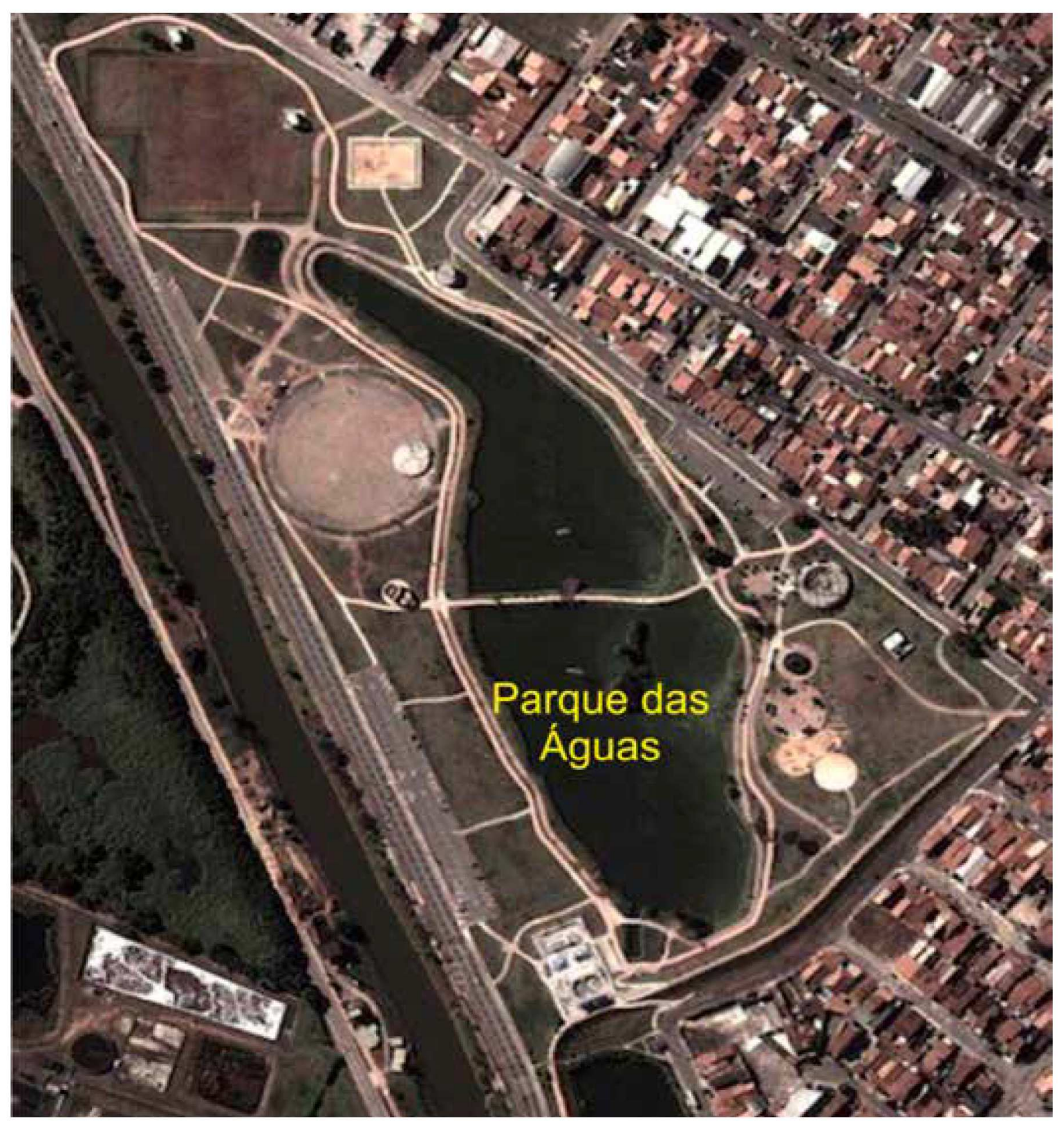

Figura 6 Estruturação do Parque das Águas.

Editada por José Roberto Merlin e Flávia Aceituno Carneiro.

Fonte: Google Earth. Disponível em: <https://www.google.com.br/maps/place/Parque+das+\%C3\%81guas/@23.4701255,-47.4461316,17z/data $=! 3 \mathrm{~m} 1$ ! $4 \mathrm{~b} 1 ! 4 \mathrm{~m} 2$ !3m 1! 1 s0x94cf5ff787200fb 1:0x2ceac4fc5ecb87d6>. Acesso em: 4 mai. 2013. 


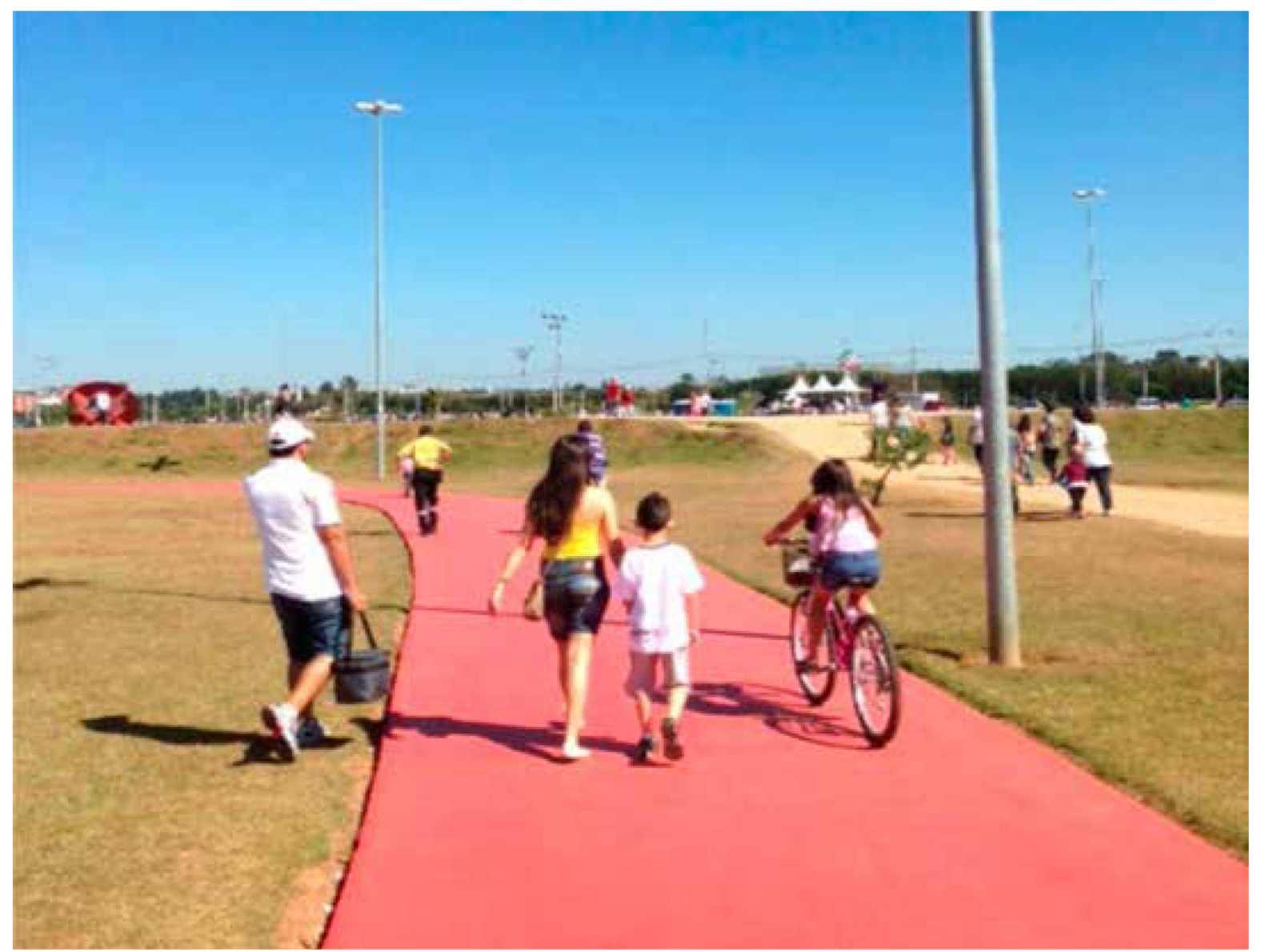

Figura 7 Pista para caminhada e ciclovia. Foto: Flávia Aceituno Carneiro - 2013.

A iluminação natural nos espaços abertos é hoje definida por composição paisagística com árvores recém-plantadas, de tamanho reduzido, que geram áreas muito ensolaradas, com pouca proteção aos transeuntes. Assim, foi necessário construir edifícios e coberturas em lona para abrigar diversas atividades específicas, como a academia ao ar livre e o espaço de brinquedos, que exigem menor incidência de luz solar - bastante refletida pelo grande lago quando as condições de clima e vento estão favoráveis.

A volumetria criada no lugar articula e define os espaços externos e revela as relações entre a geometria, adição, subtração e hierarquia. A ideia geral de adição versus subtração se desenvolve no processo que, segundo White (1984, p. 7), é: "[...] anexar, ou agregar, e de segregar formas construídas para criar arquitetura". É possível perceber a clara oposição entre o que foi construído - pista de skate, playground, base da guarda municipal, palco para eventos - e os vazios formados pelo lago central, pelas quadras de areia e pelo campo de futebol, resultando em um contraponto enriquecedor, que permite perceber relações de luzes e sombras, cheios e vazios, repetições e singularidades, áreas de uso e percursos e da hierarquia espacial que domina o conjunto. 


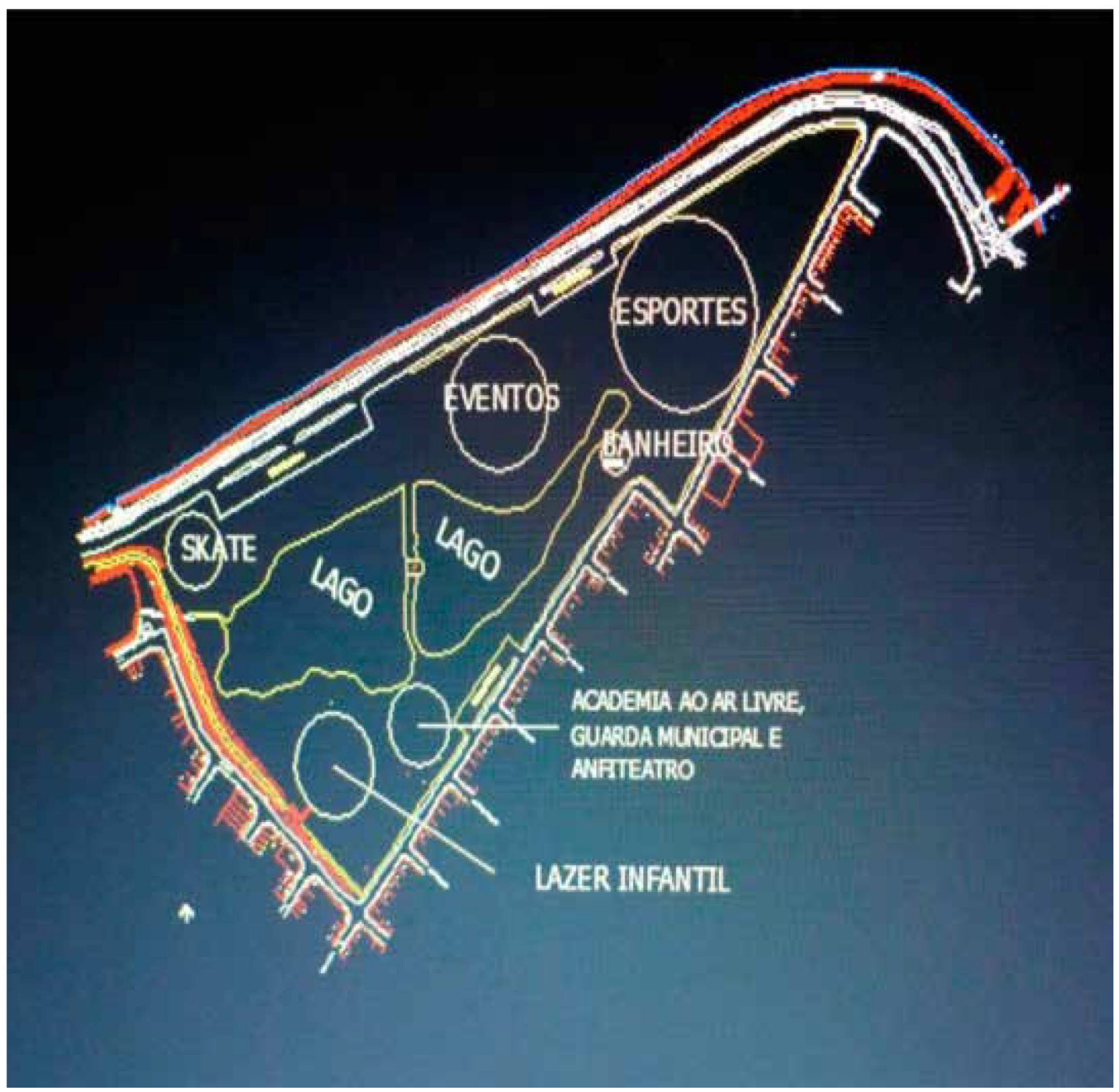

Figura 8 Uso e ocupação do espaço.

Fonte: José Roberto Merlin e Flávia Aceituno Carneiro - 2013.

Simetria e equilíbrio são conceitos utilizados desde as origens da arquitetura. $\bigcirc$ equilíbrio remonta a ideia de estabilidade perceptiva ou conceitual, já a simetria é uma forma específica de equilíbrio. Distingue-se no parque um equilíbrio compositivo que se aproxima de processos perceptivos com atributos que identificamos como equivalentes entre certos elementos da composição, que dão noção de estabilidade ao conjunto, gerando uma simetria diferente do espelhamento direto, criando tensões entre as formas.

A geometria se impõe ao delimitar a forma construída e possuir ampla gama de níveis formais e espaciais que partem de formas geométricas simples para atingir composições mais complexas e sofisticadas. A geometria aparece com extraordinário vigor na escultura vermelha e circular de aço exposta ao lado da praça de eventos, produzida por uma indústria local e criada pelo artista Chico Niedzielski. Sua escala incomum a torna imponente neste setor do parque. 


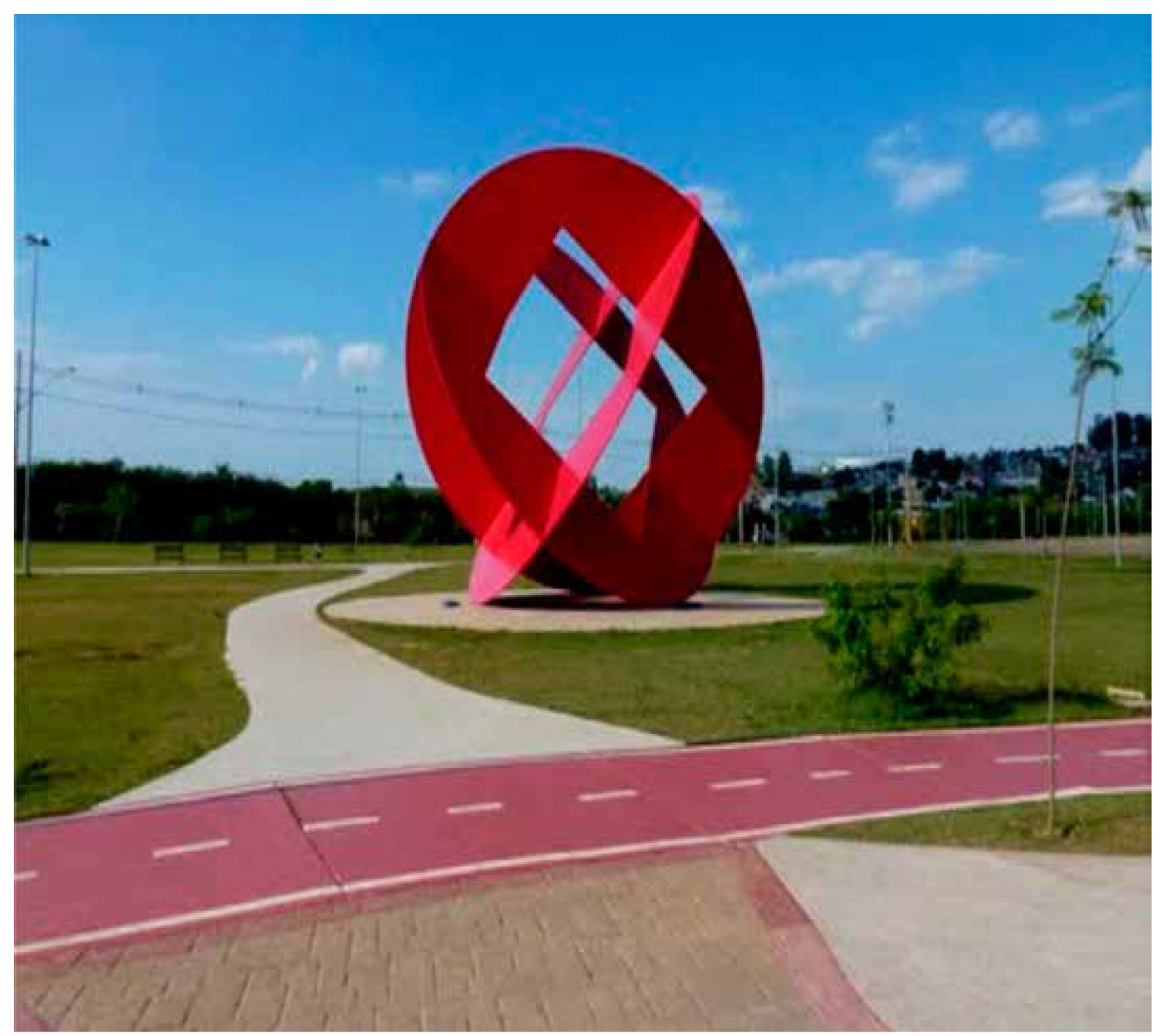

Figura 9 Escultura como destaque vertical.

Foto: Flávia Aceituno Carneiro - 2013.

A hierarquia pode ser considerada uma das geratrizes do projeto e fruto da combinação entre relações como maior e menor, horizontal e vertical, aberto e fechado, público e privado. Na horizontal, o lago é, hierarquicamente, o grande organizador e balizador espacial, seguido pelo local de eventos e pela escultura, que protagoniza a hierarquia verticalizada. Estes elementos comandam a organização espacial e todos os espaços de circulação, percursos e outras funções, como: local de ginástica, parque infantil e mesmo locais sem uso perfeitamente definido, que se estruturam através dos eixos e pontos focais, facilitando os percursos àqueles que se animam em deambular pelo parque.

\section{CONSIDERAÇÕES FINAIS}

Através dos parâmetros inclusos na Carta das Cidades Educadoras e dos cinco tópicos colocados como características e potencialidades educadoras (MERLIN; QUEIROGA, 2011) foram feitas algumas considerações sobre o potencial educador do Parque das Águas: 
a) relações com o entorno: o Parque das Águas possui íntima relação com seu entorno, já que é fruto de conexões físicas e psicológicas (vinculadas às enchentes) com a vizinhança e com ela interage através de vias locais e ciclovias, assim como desvela harmonia paisagística entre o parque com os bairros circundantes e o rio Sorocaba; o acesso, tanto por veículos como por pedestres, está adequado, cumprindo as normas de acessibilidade universal; seu desenho não agride o ambiente preexistente, dando continuidade espacial e visual entre o parque e a vizinhança;

b) história do lugar: a história do local é lembrada pela abundância de água, ponto de partida para o projeto do parque, que surgiu para resolver os constantes alagamentos das residências, sendo paradigmático ao revelar que problemas podem gerar belas soluções;

c) encontros humanos: o parque permite encontros por ser local de eventos sociais, possibilitando reunir de poucas até mais de 10 mil pessoas, pois possui infraestrutura permissiva aos encontros em diversas escalas;

d) suscitar percepções: possui lago, áreas de contemplação e estar, além de uma escultura que, enquanto arte, mexe fundamentalmente com as emoções humanas; a presença de água e os diferentes tipos de vegetação são elementos estruturais que propiciam o adestramento da sensibilidade humana;

e) qualidade do design: o projeto, embora tente agregar estética à funcionalidade, especialmente na relação da escultura com o parque, ainda não cumpre radicalmente os quesitos necessários para constituir a dignidade do lugar através da qualidade do design, pois não responde de forma primorosa aos cinco preceitos que caracterizam as obras insólitas: técnicos, funcionais, éticos, políticos e estéticos; também ainda não foi apropriado totalmente pela comunidade sorocabana, possivelmente pelo curto tempo de existência.

Resumindo, é possível dar ao espaço características que enfatizem seu processo educador, revelando conhecimentos novos aos usuários. Não se trata de conteúdos disciplinares tradicionais ou escolares, mas sim de atingir sensações, percepções e entendimentos sobre o fato de a cidade ser um lugar de encontro para superar diferenças, de entender que a linguagem da arquitetura sempre pode revelar a sociedade que a gerou, de considerar que o espaço pode evidenciar que uns aprendem com os outros pelas diferenças, e que são estas distinções que oferecem possibilidades de construção da sabedoria e do respeito à alteridade. 


\section{REFERÊNCIAS BIBLIOGRÁFICAS}

AICE - Associação Internacional das Cidades Educadoras. Carta das Cidades Educadoras. Disponível em: $<w w w . e d c i t i e s . o r g />$. Acesso em: 5 dez. 2012.

CLARK, Roger H.; PAUSE, Michael. Arquitectura: temas de composición. México: Gustavo Gili, 1987. 240 p.

GALENDER, Fanny et al. Sistema de Espaços livres urbanos de Sorocaba (SP). In: CAMPOS, A. et al. Quadro dos sistemas de espaços livres nas cidades brasileiras. São Paulo: rAUUSP, 20 I 2, p. 3 | 4-333.

MERLIN, José Roberto. Lugares públicos: possibilidades de incrementar a esfera de vida pública enfatizando processos educadores inerentes ao espaço. ENCONTRO DA ASSOCIAÇÃO NACIONAL DE PESQUISA E PÓS- GRADUAÇÃO EM ARQUITETURA E URBANISMO (ENAMPARQ), 2, Natal. CD.

; QUEIROGA, Eugenio Fernandes. Sobre espaços públicos potencialmente educadores. São Paulo: QUAPA-SEL, 2011. CD.

WHITE, Edward. Manual de conceptos de formas arquitectonicas. 3 ed. México: TRILLAS, 1984. 202 p.

\section{SITES}

<http://www.sorocaba.sp.gov.br/pagina/326>.

Acesso em: 26 mai. 2013.

$<\mathrm{http}: / /$ www.ihggs.org.br/index2.php?option =content\&do_pdf $=1$ \&id $=193>$.

Acesso em: 26 mai. 2013.

<http://www.camarasorocaba.sp.gov.br/sitecamara/historiasorocaba.html>.

Acesso em 26 mai. 2013.

Artigo recebido em 9 ago. 2013. 
